\title{
Band Gap and Raman Shift of InN Grown on Si (100) by Radio-Frequency Sputtering
}

\author{
Wang Xuewen, Li Tingting, Su Xingxing, Wu Zhaoke, Zhai Chunxue, Hu Feng, \\ Zhang Zhiyong, Zhao Wu
}

Northwest University, Xi'an 710127, China

\begin{abstract}
We have grown the InN films with high orientation and various typical micrographs on $\mathrm{Si}$ (100) substrate by radio-frequency (RF) sputtering, with Indium used as Indium target, and Nitrogen as Nitrogen source. The X-ray diffraction (XRD) and X-ray photoelectron spectroscopy (XPS) show that all the diffraction peaks are identified to be associated with the wurtzite phase of InN, with high orientation of (101), (100) and (002). The Scanning Electron Microscope (SEM) and Energy Diffraction Spectrum (EDS) reveal that the high-quality crystal films of InN with various typical microstructures could be deposited, especially the standard of the hexagon at $60 \mathrm{~W}$ and $0.4 \mathrm{~Pa}$. We also calculated the stress of $\mathrm{InN}$ films in $E_{2}$ (High) by Raman spectra with an excitative wave length $\lambda=633 \mathrm{~nm}$ at room temperature. The values of the stress are different due to various microstructures. The $A_{1}$ (LO) peaks are lower due to the high mobility. The calculated energies are 1.07, 1.13 and $1.32 \mathrm{eV}$. The XRD, SEM, XPS, Raman spectra, Hall and UV absorption characterizations demonstrate that we could grow different microstructures of thin films to meet the various requirements of sensors and other devices.
\end{abstract}

Key words: thin films; crystal growth; magnetron sputtering; stress; energy gap

$\mathrm{Al}$, In and Ga nitrides have attracted more attention due to their high electron drift velocity and small effective mass in recent years. With its wurtzite crystal structure and $0.7 \mathrm{eV}$ direct band gap, Indium nitride $(\mathrm{InN})$ is one of the most important materials in semiconductors ${ }^{[1,2]}$, prompting the extremely rapid development of optoelectronic devices, such as IR-detectors ${ }^{[3]}$, semiconductor quantum dots (QDs) ${ }^{[4]}, \mathrm{THz}$ emitters, and magnetic field sensors ${ }^{[5]}$. The $\mathrm{InN}$ with nice properties makes it be a competitive candidate for new high-speed devices. It has been fabricated by many techniques, for example, plasma-assisted molecular beam epitaxy (PA-MBE), metal organic chemical vapor deposition (MOCVD), radio-frequency (RF) sputtering, and direct current (DC) sputtering. Compared sputtering methods with PA-MBE and MOCVD methods ${ }^{[6]}$, it is less costly and the size of the deposited thin films can be very large. Y. L. Chung et al. have studied Raman scattering and Rutherford backscattering on InN films grown by PA-MBE in $2011^{[7]}$, S. Feng also grew the InN nanorods by PA-MBE in $2015^{[8]}$, J. S. Hwang grew InN on sapphire (0001) substrate using a simple resistive heated MOCVD in $2001^{[9]}$, and W. C. Ke et al. have grown high density InN/GaN nanodot by pulsed mode MOCVD in $2010^{[10]}$. And Porntheeraphat and Nukeaw studied the band gap energy $\left(E_{\mathrm{g}}\right)$ of InN thin films grown by RF magnetron sputtering in $2008^{[10]}$, Hiroyuki Shinoda and Nobuki Mutsukura researched the structural and optical properties of RF sputtered $\mathrm{InN}$ in $\mathrm{N}_{2} / \mathrm{Ar}$ mixed gases in $2006^{[11]}$, J. M. Khoshman et al. found that the energy ranged $0.88 \sim 4.1 \mathrm{eV}$ of sputtering InN onto different substrates in $2006^{[12]}$, M. Amirhoseiny et al. fabricated the wurtzite nanocrystalline (101) InN films with RF-sputtering in $2014^{[13]}$. However, there is no report preparing different morphologies and orientations $\mathrm{InN}$ film by RF-sputtering. In this paper, various topographies were grown under different process conditions of

Received date: January 16, 2017

Foundation item: National Natural Science Foundation of China (61405159, 61076002); Natural Science Foundation of Education Commission of Shaanxi Province (2012JK848)

Corresponding author: Wang Xuewen, Ph. D., Professor, School of Information Science and Technology, Northwest University, Xi'an 710127, P. R. China, Tel: 0086-29-88308119, E-mail: wangxuew@nwu.edu.cn 
RF-sputtering technology and the properties were studied.

\section{Experiment}

All InN films were deposited onto Si (100) substrates by RF magnetron sputtering. The (100) Si substrates were cleaned with ethanol, acetone and de-ionized (DI) water for 3 times before being mounted to the substrate holder in the vacuum chamber. The In metal (99.999\%), was used as targets while Ar (99.999\%) and $\mathrm{N}_{2}(99.999 \%)$ was used as working gases. The substrate temperature of the samples were kept at $600{ }^{\circ} \mathrm{C}$ for $60 \mathrm{~min}$ under the flow of $\mathrm{N}_{2}(20 \mathrm{~mL} / \mathrm{min})$ and $\operatorname{Ar}(20 \mathrm{~mL} / \mathrm{min})$. The samples $\mathrm{A}$ and $\mathrm{B}$ were grown at the air pressure of $0.6 \mathrm{~Pa}$, while the sample $\mathrm{C}$ was deposited at $0.4 \mathrm{~Pa}$. The sputtering power can be adjusted from 60 (samples B and C) to 70 (sample A) W. The structures properties of the samples were obtained by X-ray diffraction (XRD, 6100, SHIMADZU) with $\mathrm{Cu} \mathrm{K \alpha}$ radiation. The morphologies and the element compositions of the samples were measured with X-ray photoelectron spectroscopy (XPS, ESCALAB 250 XI),Scanning Electron Microscope and E nergy Diffraction Spectrum (SEM, EDS, Hitacathi S-4800). The stress of film samples were analyzed by the measurement of Raman (WITec, Alpha-500). The carrier concentration and mobility variation were measured through employing Hall system ( $\mathrm{RH}$ 2035 Hall System, PhysTech Gmbh, Germany). Energy was tested by UV absorption (UV-1800i, SHIMADZU).

\section{Results and Discussion}

\subsection{Crystal structure measurement of the samples}

The XRD patterns of thin film samples which grew on the Si (100) substrate at $600{ }^{\circ} \mathrm{C}$ with different sputtering powers and air pressures are shown in Fig.1. And the XPS patterns are shown in Fig.2. Sample A was prepared under 0.6 $\mathrm{Pa}$ air pressure while the sputtering power was $70 \mathrm{~W}$, Sample B was deposited at $60 \mathrm{~W}$ under $0.6 \mathrm{~Pa}$, while sample $\mathrm{C}$ was grown at $60 \mathrm{~W}$ under $0.4 \mathrm{~Pa}$.

In Fig.1, all the diffraction peaks are identified to be assoc ated with the wurtzite phase of InN (PDF 50-1239) ${ }^{[14]}$. It can be seen that the InN films are preferentially oriented in

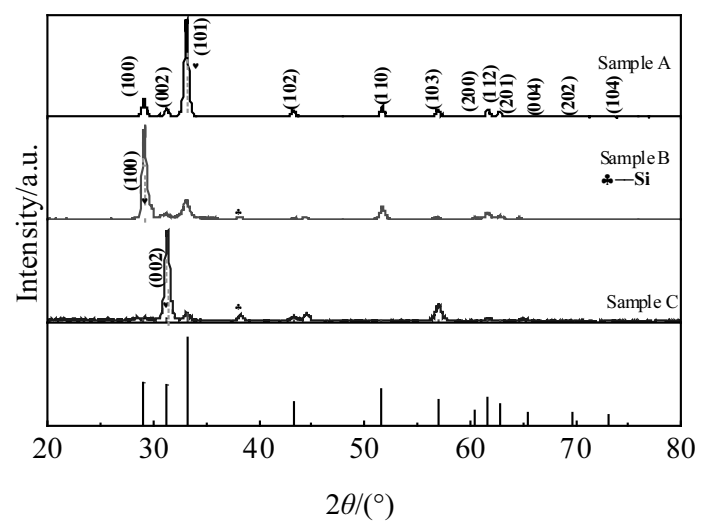

Fig.1 XRD patterns of the $\mathrm{InN}$ thin films different directions. That is in detail, the stronger peak at $33.14^{\circ}$ in the sample A, $29.16^{\circ}$ in the sample B, and $31.32^{\circ}$ in the sample $\mathrm{C}$, which are the diffractions assigned to the (101), (100) and (002) respectively of the wurtzite type InN. All diffraction peaks in the sample A can be indexed to cubic phase and hexagonal $\mathrm{InN}$ structure ${ }^{[15]}$. Another peak at $38.783^{\circ}$ is due to the $(100)$ diffraction of $\mathrm{Si}$ substrate in the sample B and C of Fig.1. The bigger reflection width $\left(1^{\circ}\right)$ which is FWHM (full width at half maximum) suggests that the grain size belongs to large particles, and the sharpness of the InN spectral is consistent with good crystalline quality. The film preferentially oriented in (101) direction grew on $\mathrm{Si}$ (100) at $70 \mathrm{~W}$ with $0.6 \mathrm{~Pa}$, and the InN sample B with (100) direction preferentially oriented could be compounded when the sputtering power changed to $60 \mathrm{~W}$, and then the $\mathrm{InN}$ sample $\mathrm{C}$ would preferentially orient to $c$-axis (002) when the air pressure decreased from 0.6 to $0.4 \mathrm{~Pa}$.

We used XPS spectra to analyze the surface composition of InN. Each element peak was revised by the C $1 \mathrm{~s}(284.8 \mathrm{eV})$. From the wide scan XPS spectra, we can see that there are three elements on the surface of InN, In, N, and O in Fig.2. The peaks at the position of 443.8, 451.4, $398.4 \mathrm{eV}$ correspond to In $3 \mathrm{~d}_{5 / 2}$, In $3 \mathrm{~d}_{3 / 2}, \mathrm{~N} 1 \mathrm{~s}$ peak, respectively. Compared to the paper reported by Harish Parala, the results of In $3 d_{5 / 2}$ and In $3 d_{3 / 2}$ are almost same ${ }^{[16]}$. But in the report of Qiang Jing, the two binding energy are high, because of a series of Auger peaks of Indium in the XPS spectra ${ }^{[17]}$. The binding energy of InN in this paper are basically identical with the standard material. Therefore we can accurately determine the energy loss peak of the most clean samples. For the $\mathrm{O}$ elements appearing in $\mathrm{InN}$, we consider it comes from $\mathrm{O}_{2}$ in the air. Because in a wet environment, $\mathrm{O}_{2}$ is more easily absorbed on the substrates, so we use XPS spectra to analyse the form of the $\mathrm{O}$ element. From the formula:

$$
X=\left[A_{x} / S_{x}\right] / \sum_{i=1}^{N} A_{i} / S_{i}
$$

We can calculate the percentage contents of each elements. Here, $X$ is element percentage. $A_{x}$ is the area of the peak, and $S_{x}$ is a sensitivity factor of the element. On the InN surface, In

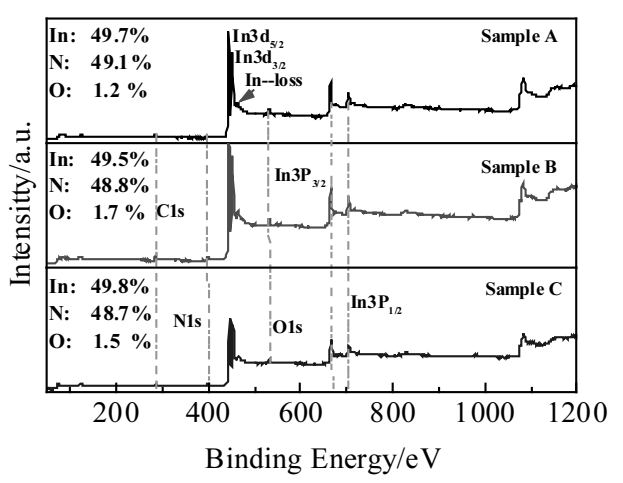

Fig.2 XPS patterns of the $\mathrm{InN}$ thin films 
and $\mathrm{N}$ atomic ratio is about $1: 1$. It is consistent with the result of EDS shown in Table 1, which further show that the quality of laboratory prepared $\mathrm{InN}$ thin film is very high ${ }^{[18]}$.

\subsection{Microstructure Analysis of the samples}

Fig. 3 shows the typical SEM micrographs and the EDS spectrum of the top surface view of InN films which grew on the $\mathrm{Si}(100)$ substrate. It can be found that the epitaxy of InN films change as the sputtering powers are decreased from 70 to $60 \mathrm{~W}$, and the pressures are reduced from 0.6 to $0.4 \mathrm{~Pa}$. It can be concluded that the micrograph of sample $\mathrm{A}$ is a rectangle, because the sample A was grown in stronger (101) direction in Fig.1, and average size of the gains is about 600 $\mathrm{nm}$. When sample B deposited in (100) direction in Fig.1, the triangular edges can be seen clearly in the Fig.3b, the average size is about $200 \mathrm{~nm}$. The standard hexagon on the top surface is found in Fig.3c due to the orient in the $c$-axis (002), and the average size of the gains is about $150 \mathrm{~nm}$. H. Sugiura et al. ${ }^{[19]}$ have explored the same microtopography result. The size of crystalline grains is expanded $(600>200>150 \mathrm{~nm})$ with In and $\mathrm{N}$ ions increasing due to the increasing of the power and the pressure. The crystalline grains shown in Fig.3 are various micrographs of typical wurtzite, which mutually corroborate with the result of the reflection widths in Fig.1. It can be found that the surface is very smooth. We hardly find any other impurity elements except $\mathrm{Si}$ substrate and $\mathrm{O}$ in EDS spectrum and Table 1, which can be seen in Fig.1.

Table 1 shows the percentages of elements in the sample A, $\mathrm{B}$ and C. All the samples are slightly In rich. It is clear that the
In content increases with the increase of the sputtering power. The rate of In:N:O increases from 1:0.97:0.03 to 1:0.98:0.034 by reducing the air pressure. From this, it can be concluded that the sputtering power and pressure play an important role in depositing InN films. High power is conducive to the reaction of In atom, and lower pressure is beneficial to the synthesis of $\mathrm{InN}$ which improve the electrical properties, because the positions of potential minima are occupied by more activation energy with high power ${ }^{[20]}$. Thus by changing the power and the pressure, high-quality crystal films of InN with various typical micrographs could be deposited. We can find the same results from XPS test.

Table 1 Composition of InN films synthesized on Si (100) substrates

\begin{tabular}{ccc}
\hline Sample & Element & at\% \\
\hline A & N & 49.1 \\
& In & 49.7 \\
& O & 1.2 \\
\hline B & N & 48.8 \\
& In & 49.5 \\
& O & 1.7 \\
\hline C & N & 48.7 \\
& In & 49.8 \\
& O & 1.5 \\
\hline
\end{tabular}

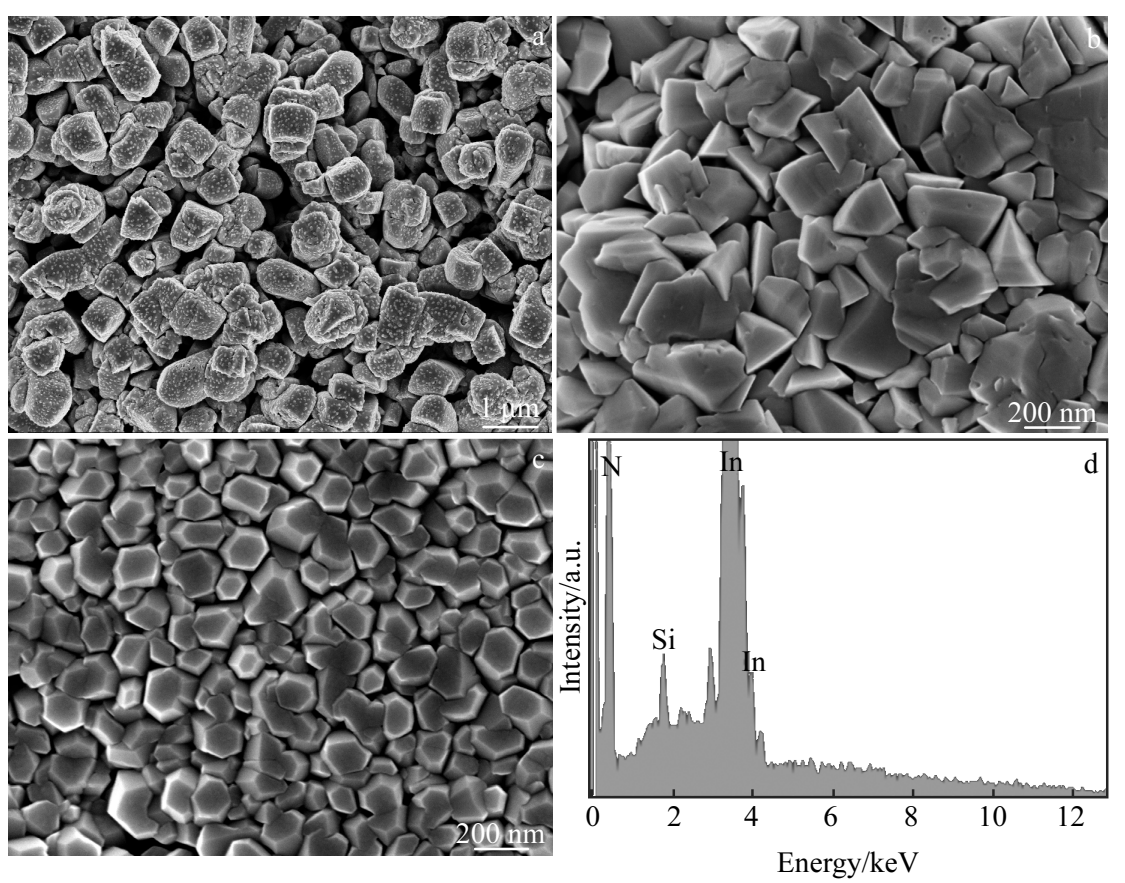

Fig.3 Typical SEM micrographs of InN structures deposited at various powers and air pressures: (a) $70 \mathrm{~W}, 0.6 \mathrm{~Pa}$, (b) $60 \mathrm{~W}, 0.6 \mathrm{~Pa}$, and (c) $60 \mathrm{~W}, 0.4 \mathrm{~Pa}$; (d) EDS spectrum of sample A 


\subsection{Surface Raman analysis}

The Raman spectra of sample A, B, and C with an excitation wavelength $\lambda=633 \mathrm{~nm}$ at room temperature are shown in Fig.4. Peaks at 585, 586, and $586 \mathrm{~cm}^{-1}$ are assigned to $A_{1}(\mathrm{LO})$ of InN films. The $E_{2}$ (High) peaks of sample A, B, and $\mathrm{C}$ are observed at $490.88,490$, and $492.51 \mathrm{~cm}^{-1}$ respectively. The $E_{2}$ phonon mode of the $\mathrm{InN}$ film in the Raman spectra is affected by the presence of residual stress in the film; hence the strain present in the $\mathrm{InN}$ film can be measured ${ }^{[14]}$. Besides the InN phonon modes, a phonon mode at $520 \mathrm{~cm}^{-1}$ from the $\mathrm{Si}(100)$ substrate is also observed in the sample A, B, and C. The stresses obtained by the position of $E_{2}$ (High) in Fig.4 are determined by the equation that $\mathrm{C}$. Pinquier et al. reported ${ }^{[21,22]} . \Delta \omega=K_{\mathrm{b}} \sigma_{\mathrm{b}}$, where $\Delta \omega$ is the Raman shift in $\mathrm{cm}^{-1}, K_{\mathrm{b}}=5.6$ and $\sigma_{\mathrm{b}}$ is the stress expressed in GPa. The InN is freestanding while the $E_{2}$ (High) peak position is expected to be at $490 \mathrm{~cm}^{-1[23]}$.

Therefore, the values of $\sigma_{\mathrm{b}}$ are calculated to be $+0.16,0$, and $+0.44 \mathrm{GPa}$ corresponding to the sample A, B, and C, respectively. That is the sample $\mathrm{B}$ which is grown stress-free. The values of $\sigma_{\mathrm{b}}$ are higher than the reported -0.078 and $-0.196 \mathrm{GPa}^{[14]}$, due to the large lattice mismatch and the difference of thermal expansion coefficient between InN films and Si (100) substrates ${ }^{[20]}$. The sample B is stress-free because the small lattice mismatch between InN films is preferentially oriented with (100) direction in Fig.1 and Si (100) substrates. However, there is a large lattice mismatch between the samples A with (101) direction and C with (002) direction in Fig.1 and $\mathrm{Si}(100)$ substrates, leading to the higher values of $\sigma_{\mathrm{b}}$ than sample B, especially sample C.

\subsection{Carrier concentration and mobility variation analysis}

As shown in Table 2, the samples of $\mathrm{A}, \mathrm{B}$, and $\mathrm{C}$ have high electron mobility with weak peaks of $A_{1}(\mathrm{LO})^{[14]}$. Therefore, the technologies provide samples better crystallinity and higher mobility.

Carrier concentration and mobility variation are measured through employing Hall system shown in Table 2.

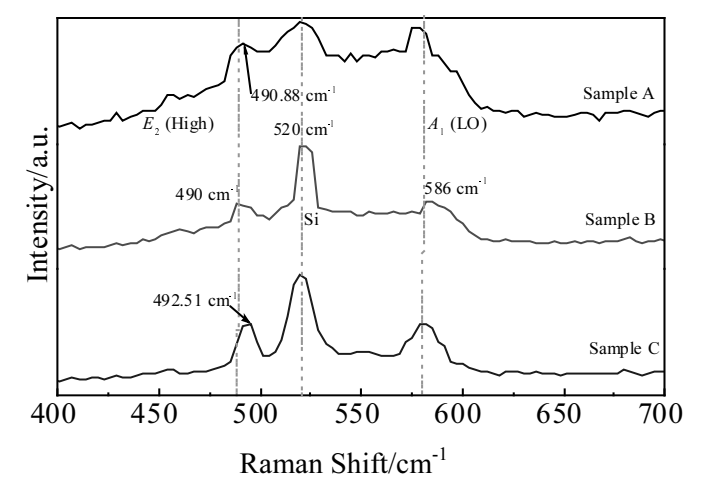

Fig.4 Raman spectra of InN grown on Si (100) of sample A, B, and $\mathrm{C}$ with an excitation wavelength $\lambda=633 \mathrm{~nm}$ at room temperature
Table 2 Hall tests of samples A, B and C

\begin{tabular}{ccccc}
\hline Sample & Type & $\begin{array}{c}\text { Electrical } \\
\text { resistivity } / \Omega \cdot \mathrm{cm}\end{array}$ & $\begin{array}{c}\text { Carrier } \\
\text { concentration } / \mathrm{cm}^{-3}\end{array}$ & $\begin{array}{c}\text { Mobility/ } \\
\mathrm{cm}^{2} \cdot(\mathrm{V} \cdot \mathrm{s})^{-1}\end{array}$ \\
\hline $\mathrm{A}$ & $\mathrm{n}$ & $1.30 \times 10^{3}$ & $3.37 \times 10^{17}$ & 197 \\
$\mathrm{~B}$ & $\mathrm{n}$ & $2.59 \times 10^{2}$ & $2.16 \times 10^{18}$ & 223 \\
$\mathrm{C}$ & $\mathrm{n}$ & $1.21 \times 10^{3}$ & $6.58 \times 10^{17}$ & 201 \\
\hline
\end{tabular}

From Table 2, it can be found that the mobilities of samples $\mathrm{A}, \mathrm{B}$ and $\mathrm{C}$ are $197 \sim 223 \mathrm{~cm}^{2} /(\mathrm{V} \cdot \mathrm{s})$, which are similar to the report of Barick, B. $\mathrm{K}^{[24]}$. The peak of $A_{1}(\mathrm{LO})$ in Fig.3b is lower than that of samples $A$ and $B$, which suggest that the mobility of sample B is higher than that of A and C. The test of hall shows the same result in Table 2. All type of samples are $\mathrm{n}$, because the films are In rich shown in Table 1. From the results of XRD, SEM, EDS and Raman, impure phases are not found, meaning that the surfaces of samples $\mathrm{A}, \mathrm{B}$ and $\mathrm{C}$ are smoother and the mobility would be increased with the impurities and defects decreasing.

The band gap energy of our samples and some references are presented in Table $3^{[25]}$. And the energy curves of InN with different experimental conditions are shown in Fig.5. Compared with those references using the same method, the prepared samples shows lower band gap energy. Because the experiment background vacuum degree is higher, the oxygen content is smaller than the references. From the result of EDS, we can see that the oxygen content of sample A is minimum, so the $E_{\mathrm{g}}$ is the minimum. However, sample $\mathrm{B}$ has more oxygen, so its $E_{\mathrm{g}}$ is higher, but less than $2 \mathrm{eV}$. This phenomenon is close to the result from Davydov et al. who thought the band gap energy is close to $2 \mathrm{eV}$ when oxygen content is close to $20 \%$. The band gap of InN thin film is the smallest, and the crystal quality is the best. V. Y. Davydov et al thought the possible reason for the $1.9 \mathrm{eV}$ band gap is the doping of the impurity oxygen during magnetron sputtering. When the oxygen content was up to $20 \%$, the band gap energy of InN was close to $2 \mathrm{eV}^{[26]}$.

At present, the band gap of $\mathrm{InN}$ is $0.9 \mathrm{eV}$ (room temperature), while it is widely believed that the intrinsic band gap of $\mathrm{InN}$ was $1.9 \mathrm{eV}$ in the early. In this paper, we can get various band gap of InN under different pressure and power of sputtering by ultraviolet absorption spectrum fitting. The relations between the absorption coefficient and the band gap $E_{\mathrm{g}}$ is:

$$
\alpha(h v) \infty\left(h v-E_{\mathrm{g}}\right)^{\frac{1}{2}}
$$

Where $h$ is the Planck constant and $v$ is the incident light

Table 3 UV absorption tests of samples A, B and C

\begin{tabular}{ccccc}
\hline Sample & $\begin{array}{c}\text { Sputtering } \\
\text { stress/Pa }\end{array}$ & $\begin{array}{c}\text { Sputtering } \\
\text { power/W }\end{array}$ & $E_{\mathrm{g} / \mathrm{eV}}$ & $E_{\mathrm{g}(\mathrm{Ref} .)} / \mathrm{eV}$ \\
\hline $\mathrm{A}$ & 0.6 & 70 & 1.07 & 2.03 \\
$\mathrm{~B}$ & 0.6 & 60 & 1.32 & 2.1 \\
$\mathrm{C}$ & 0.4 & 60 & 1.13 & 1.97 \\
\hline
\end{tabular}




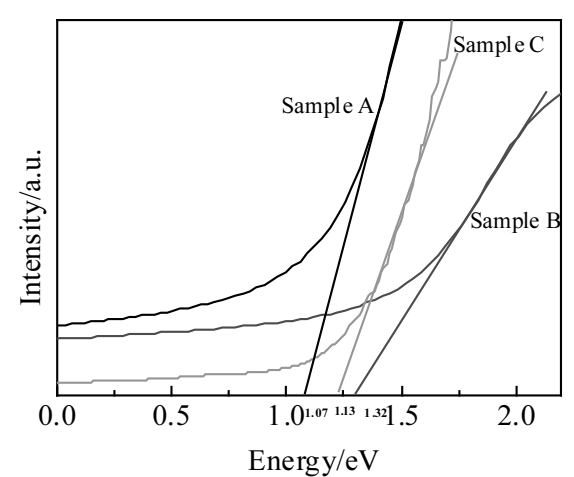

Fig.5 Energy curves of InN with different experimental conditions

frequency ${ }^{[27]}$. According to the absorption spectrum and this formula, we can get the energy curves in Fig.5. Thus getting the band gap values also means that the value of the optical band gap energy can be approximately determined by the intercept of a linear fit to this curve with the energy axis ${ }^{[28]}$. The experiment proved that $E_{\mathrm{g}}$ of $\mathrm{InN}$ is not only related to the carrier concentration, but also to the pressure and power of the sputtering. The different pressure lead to the average kinetic energy different of films. In Fig.5, we can get the band gap energy of 1.07 and 1.13 and $1.32 \mathrm{eV}$ of $\mathrm{InN}$ thin film through different sputtering pressures and power.

Different references of the band gap values of the $\mathrm{InN}$ are given in Table 3. Compared with the band gap values in the references, our band gap valueis smaller. While Davydov et al. believed that the entrance of $\mathrm{O}_{2}$ makes the $\mathrm{O}$ atom destroy the In-N key and forms the $\operatorname{In}_{2} \mathrm{O}_{3}$ which lead to the changing of InN structure; hence the band gap energy of $\mathrm{InN}$ thin films are increased $^{[29]}$.

W. Walukiewicz proved that the band gap energy of $\mathrm{InN}$ thin films increases as the carrier concentration increases ${ }^{[28]}$, When the carrier concentration is high enough, the bottom of the conduction band will be filled by the carriers. We need more excitation energies than the former band gap if we want to excite the electronics of the valence band to the conduction band which can broaden the optical band gap of film, and give rise to the absorption edge of the film moves towards the short wavelength direction (The increase of the carrier concentration leads to the blue shift of the optical band gap). From this property, we can acquire the continuous tunable direct band gap when we adjust the proportions between the $\mathrm{InN}$ and any other group III semiconductor materials, thus developing a photoelectric device in which the photoelectric properties can range from the near infrared to the deep ultraviolet spectrum. The result is consistent with Hall test.

\section{Conclusions}

1) Changing the power and pressure, we can get different directions of samples.

2) From the SEM micrographs, the standard hexagon can be grown at $0.4 \mathrm{~Pa}$ and $60 \mathrm{~W}$, and other typical micrographs can be deposited at $0.6 \mathrm{~Pa}$, which would be available for gas sensor in the future.

3) Raman spectroscopy reveals that the stress-free film can be grown on $\mathrm{Si}(100)$ at $60 \mathrm{~W}$ with $0.6 \mathrm{~Pa}$, which is helpful to form an air-bridge-like structure with a high aspect ratio ${ }^{[30]}$.

4) The films with lower $A_{1}$ (LO) have the high electron mobl ity shown in the Hall test, and the energy of films are less than $1.9 \mathrm{eV}$ which may be available for high-power device.

\section{References}

1 Porntheeraphat S, Nukeaw J. Applied Surface Science[J], 2008, 254(23): 7851

2 Cai X M, Ye F, Hao Y Q et al. Journal of Alloys \& Compounds [J], 2009, 484(1-2): 677

3 Amirhoseiny M, Hassan Z, Ng S S et al. Vacuum[J], 2014, 106(8): 46

4 Shen C H, Lin H W, Lee H M et al. Thin Solid Films[J], 2006, 494(1): 79

5 Ivanov S V, Shubina T V, Komissarova T A et al. Journal of Crystal Growth[J], 2014, 403(10): 83

6 Bi Z X, Zhang R, Xie Z L et al. Journal of Materials Science[J], 2007, 42(15): 6377

7 Chung Y L, Peng X, Ying C L et al. Thin Solid Films[J], 2011, 519(20): 6778

8 Feng S, Tan J, Li B et al. Journal of Alloys \& Compounds[J], 2015, 621: 232

9 Hwang J S, Lee C H, Yang F H et al. Materials Chemistry \& Physics[J], 2001, 72(2): 290

10 Ke W C, Lee S J, Kao C Y et al. Journal of Crystal Growth[J], 2010, 312(21): 3209

11 Shinoda H, Mutsukura N. Thin Solid Films[J], 2006, 503(1-2): 8

12 Khoshman J M, Kordesch M E. Journal of Non-Crystalline Solids [J], 2006, 352(52-54): 5572

13 Amirhoseiny M, Hassan Z, Ng S S. Vacuum[J], 2014, 101(3): 217

14 Roul B, Rajpalke M K, Bhat T N et al. Journal of Crystal Growth[J], 2012, 354(1): 208

15 Yaguchi H, Kitamura Y, Nishida K et al. Physica Status Solidi [J], 2005, 2(7): 2267

16 Parala H, Devi A, Hipler F et al. Journal of Crystal Growth[J], 2001, 231(1-2): 68

17 Jing Q, Yang H, Li W et al. Applied Surface Science[J], 2015, 331: 248

18 Chauhan A K S, Kumar M, Gupta G. Applied Surface Science [J], 2015, 345: 156

19 Sugiura H, Wakasugi S, Mizutani H et al. Materials Chemistry \& Physics[J], 2008, 108(2): 176

20 Qian Z G, Yu G, Shen W Z et al. Physica B Condensed Matter [J], 2002, 318(2-3): 180

21 Wang X, Su X, Hu F et al. Journal of Alloys \& Compounds [J], 2016, 667: 346 
22 Pinquier C, Demangeot F, Frandon J et al. Phys Rev $B[\mathrm{~J}]$, 2004, 70(11): 2516

23 Wang X, Che S B, Ishitani Y et al. Applied Physics Letters[J], 2006, 89(89): 171907

24 Barick B K, Dhar S. Journal of Crystal Growth[J], 2015, 416: 154

25 Guo Q X, Tanaka T, Nishio M et al. Applied Physics Letters[J], 2005, 86(23): 231913

26
Solidi [J], 2002, 234(3): 787

27 Zhao Y, Wu G, Leng J et al. Vacuum[J], 2016, 124: 72

28 Schoche S, Hofmann T, Darakchieva V et al. Journal of Applied Physics[J], 2013, 113(1): 013502

29 Sasaoka T, Mori M, Miyazaki T et al. Journal of Applied Physics[J], 2010, 108(6): 063538

30 Vajpeyi A P, Ajagunna A O, Tsiakatouras G et al. Microelectronic Engineering[J], 2009, 86(s4-6): 812

\title{
采用磁控溅射法在 Si（100）生长 InN 薄膜及其禁带宽度与拉曼的测试
}

\author{
王雪文, 李婷婷, 苏星星, 吴朝科, 翟春雪, 胡 峰, 张志勇, 赵 武
}

(西北大学, 陕西 西安 710127)

\begin{abstract}
摘 要: 采用磁控贼射法在 $\mathrm{Si}(100)$ 祄底上生长出高取向性和多种微观形貌的 $\mathrm{InN}$ 薄膜, 其中铟作为铟靶, 氮气作为氮源。 $\mathrm{X}$ 射线衍 射 (XRD) 和 X 射线光电子能谱 (XPS) 表明所有衍射峰和标准的纤锌矿晶型的 InN 一致, 并且在 (101), (100) 和 (002) 方向具有极高 的取向度。扫描电子显微镜(SEM)和能带衍射谱表明, 在 $\mathrm{Si}(100)$ 祄底上可以生长出高质量的不同微观结构的 InN 晶体薄膜, 尤其是溅射 功率为 $60 \mathrm{~W}$, 贼射压强为 $0.4 \mathrm{~Pa}$ 时表现为标准的正六边形结构。在室温下并且激发波长为 $\lambda=633$ 的拉曼测试表明, 可以通过 $E_{2}$ (High) 峰计算出 InN 薄膜的应力, 由于微观结构的不同导致应力值也不同, $A_{1}(\mathrm{LO})$ 峰值比较低是由于迁移率较高导致。紫外吸收测试可以计算 出的能带宽度分别为 $1.07,1.13,1.32 \mathrm{eV}$ 。XRD、SEM、XPS、霍尔效应、紫外吸收和拉曼光谱证明生长出的不同微观结构的薄膜可以 适应各种需求的传感器和其他设备。
\end{abstract}

关键词: 薄膜; 晶体生长; 磁控溅射; 应力; 禁带宽度

作者简介: 王雪文, 女, 1964 年生, 博士, 教授, 西北大学信息科学与技术学院, 陕西 西安 710127, 电话: 029-88308119, E-mail: wangxuew@nwu.edu.cn 